\title{
Rancang Bangun Slider Otomatis Untuk Kamera dan Smartphone Menggunakan Metode Face Tracking
}

\author{
Syauq iNur Aziz ${ }^{1}$, Galih Mustiko Aji ${ }^{2}$, Erna Alimudin ${ }^{3}$ \\ Teknik Elektro, Poiteknik Negeri Cilacap ${ }^{13}$ \\ J1 Dr Soetomo Kabupaten Cilacap, Jawa Tengah \\ ${ }^{1}$ Aziz.nur29@gmail.com
}

Abstrak- Pembelajaran jarak jauh (PJJ) yang dilaksanakan secara online membutuhkan alat atau perangkat sebagai penunjang interaksi antara tenaga pendidik dengan anak didik atau sebaliknya. Salah satu PJJ yang saat ini dapat dilaksanakan melalui media online yaitu Ujian Praktek dan Sidang Tugas Akhir. Terkadang saat dilakukannya perekaman, ada kecenderungan pembicara tidak bisa diam saat perekaman, atau bergeser dari posisi semula. Oleh karena itu untuk memudahkan proses perekaman vidio dapat menggunakan alat bantu yang disebut slider dengan prinsip kerja yaitu menggerakan kamera atau smartphone dengan bergerak mengikuti pergerakan wajah secara otomatis. Dengan menggunakan kinerja face tracking dan mengaplikasikan webcam yang digunakan sebagai sensor kamera, kemudian citra wajah akan dideteksi dan diproses menggunakan modul library OpenCV dengan menggunakan bahasa pemrograman python dan mikrokomputer Raspberry $\mathbf{P i}$ 4B yang digunakan sebagai sistem operasi pada alat dengan menggunakan LCD TFT 3,5 inch sebagai media kontrol. Hasil Tugas Akhir ini menyimpulkan bahwa faktor intensitas cahaya, jarak, dan kualitas sensor kamera sangat berpengaruh pada saat proses pendeteksian dan pengenalan wajah. Jarak ideal slider agar proses pendeteksian, pengenalan, dan penyelerasan dapat berjalan maksimal yaitu $40-100 \mathrm{~cm}$. Penggunaan material pada mekanik slider juga sangat berpengaruh pada pergerakan slider. Semakin kuat material yang digunakan maka pergerakan slider akan semakin kokoh dan stabil. Dengan adanya delay 3 detik per $10 \mathrm{~cm}$ gerakan maka slider dapat bekerja menyelaraskan gerak kamera dengan gerak wajah dengan rata - rata keberhasilan penyelarasan sebesar $41,69 \%$.

\section{Kata kunci: Face Tracking, OpenCV, PJJ, Raspberry Pi 4B, Slider}

Abstract - Distance learning (PJJ) which is carried out online requires tools or devices to support interaction between educators and students or vice versa. One of the PJJs that can currently be implemented through online media is the Practical Exam and Final Assignment Session. Sometimes when recording is done, there is a tendency for the speaker to not be silent while recording, or to shift from its original position. Therefore, to facilitate the video recording process, you can use a tool called a slider with the working principle of moving the camera or smartphone by moving to follow the movement of the face automatically. By using face tracking performance and applying a webcam that is used as a camera sensor, then facial images will be detected and processed using the OpenCV library module using the python programming language and the Raspberry $P i \quad 4 B$ microcomputer which is used as an operating system on the device using a 3.5 inch TFT LCD. as a control medium. The results of this final project conclude that the factors of light intensity, distance, and camera sensor quality are very influential during the face detection and recognition process. The ideal distance for the slider so that the detection, recognition, and synchronization process can run a maximum of $40-100 \mathrm{~cm}$. The use of materials in the mechanics of the slider is also very influential on the movement of the slider. The stronger the material used, the more sturdy and stable the movement of the slider will be. With a delay of 3 seconds per $10 \mathrm{~cm}$ of movement, the slider can work to align the camera motion with facial movements with an average alignment success of $41.69 \%$.

Keywords Eggs, LDR, Smartphone, Google Spreadsheet, Android Application.

\section{PENDAHULUAN}

Pembelajaran jarak jauh (PJJ) yang dilaksanakan secara online membutuhkan alat atau perangkat sebagai penunjang interaksi antara tenaga pendidik dengan anak didik atau sebaliknya. PJJ yang dilakukan mengalami beberapa kesulitan, salah satunya yaitu materi yang diberikan guru atau dosen belum tersampaikan kepada murid atau mahasiswa dengan baik dikarenakan perekaman vidio pembelajaran yang kurang maksimal. Vidio pembelajaran yang baik yaitu vidio yang mendapatkan seluruh rekaman kegiatan yang dilakukan oleh pembicara, karena saat pembicara bergeser akan membuat kamera tidak menangkap dengan hasil yang bagus ${ }^{[1]}$.

Terkadang saat dilakukannya perekaman, ada kecenderungan pembicara tidak bisa diam saat perekaman, atau bisa dibilang bergeser dari posisi semula. Untuk memudahkan teknik pergerakkan alat perekam vidio yaitu dengan menggunakan alat bantu yang disebut slider $^{[2]}$.

Peningkatan media atau sarana dan prasarana dimaksudkan untuk mengurangi dan mengatasi kesulitan kesulitan yang dialami guru atau dosen dan murid atau mahasiswa pada saat melakukan PJJ. Salah satu PJJ yang saat ini dapat dilaksanakan melalui media online yaitu Ujian Praktek dan Sidang Tugas Akhir. Pada umumnya pelaksanaan Ujian Praktek dan Sidang Tugas Akhir masih dilaksanakan secara offline atau langsung. Hal ini menyebabkan penurunan 
tingkat kewaspadaan terhadap penularan COVID-19, dikarenakan masih terdapat kerumunan yang terjadi pada saat proses kegiatan tersebut berlangsung. Salah satu alasan yang menyebabkan pelaksanaan ujian praktek dan Sidang Tugas Akhir dilakukan secara offline yaitu tidak adanya alat yang membantu perekaman yang secara otomatis mengikuti pergerakan guru atau dosen dan siswa atau mahasiswa. Maka dibutuhkan suatu metode yang dapat memindai dan menentukan titik acuan pergerakan kamera agar mempermudah dalam merespon dan mengikuti gerakan objek dengan menggunakan alat bantu perekaman vidio berupa slider kamera yang bergerak secara otomatis mengikuti gerak wajah presenter.

Penelitian mengenai slider kamera otomatis sebelumnya pernah dilakukan oleh Okky Pratama Pangestu, dengan menerapkan metode fuzzy Logic sugeno. Pada saat melakukan pengujian, slider kamera dapat bergerak otomatis mengikuti pergerakan objek untuk mengambil foto dan merekam vidio. Penggunaan metode fuzzy Logic sugeno berfungsi untuk menstabilkan posisi kedudukan kamera secara otomatis apabila terjadi perubahan sudut. Namun, penggunaan metode fuzzy Logic sugeno yang diterapkan memiliki kekurangan yaitu sistem tidak bisa membedakan antara objek yang direkam dengan objek lainnya yang tidak direkam. Metode lain yang berkaitan dengan identifikasi biometrik diterapkan oleh Criyus, dkk. Pengenalan wajah diterapkan untuk sistem keamanan akses ruangan pribadi dengan metode haar cascade classifier. Hasilnya, wajah yang dijadikan sebagai setpoint dapat dikenali dan sistem keamanan dapat membuka dan mengunci secara otomatis. Pada proses pengenalan wajah terdapat identifikasi atau verifikasi sebuah citra wajah yang tidak diketahui dengan algoritma komputasi, dan membandingkannya dengan data wajah yang ada ${ }^{[3]}$. Hal ini menunjukkan bahwa wajah dapat dijadikan sebagai identitas biometrik yang dikenali untuk input pada sistem pergerakan slider kamera.

Setelah meninjau efektifitas penggunaan slider pada mekanisme pergerakan kamera dan metode haar cascade classifier untuk mendeteksi dan mengenali wajah, dengan merancang sebuah alat yang dapat digunakan untuk memberi kemudahan melaksanakan kegiatan PJJ dalam melakukan proses perekaman pada pembuatan vidio pembelajaran dengan prinsip kerja alat yaitu slider akan menggerakan kamera atau smartphone dengan bergerak mengikuti pergerakan wajah secara otomatis menggunakan kinerja face tracking dengan mengaplikasikan webcam yang digunakan sebagai sensor kamera, kemudian citra wajah akan dideteksi dan diproses menggunakan modul library OpenCV dengan menggunakan bahasa pemrograman python dan mikrokomputer raspberry pi yang digunakan sebagai sistem operasi pada alat dengan menggunakan LCD TFT 3,5 inch sebagai media kontrol.

\section{METODE PENELITIAN}

\section{A. Diagram Blok Sistem}

Diagram blok merupakan salah satu bagian dalam perancangan pembuatan alat ini, karena dari diagram blok ini dapat diketahui prinsip kerja keseluruhan rangkaian. Mempermudah proses perancangan pembuatan alat sehingga akan terbentuk suatu sistem yang sesuai dengan perancangan sebelumnya. Diagram blok dari sistem alat ini dapat dilhat pada Gambar 3.2.

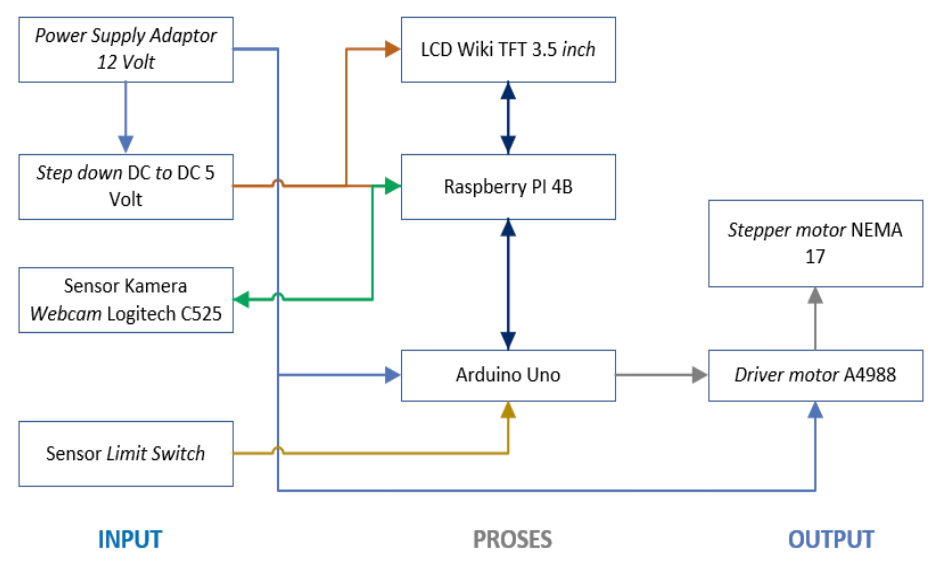

Gambar 1. Blok Diagram Sistem

Pertama - tama sistem akan bekerja dengan input Power Adaptor 12 volt yang output tegangannya digunakan sebagai sumber daya bagi Arduino Uno, driver motor A4988, dan motor stepper Nema 17. Kemudian tegangan 12 volt tersebut diturunkan menjadi 5 volt menggunkaan modul stepdown LM2596 yang digunakan untuk sumber daya bagi Raspberry Pi 4B, LCD Wiki TFT 3.5 inch, dan sensor - sensor yang digunakan seperti sensor kamera webcam, dan sensor limit switch. Kemudian sistem akan bekerja dengan input dari sensor kamera webcam, kemudian hasil penginderaan sensor kamera akan diteruskan ke proses pengolahan data pada mikrokomputer Raspberry $\mathrm{Pi} 4 \mathrm{~B}$, setelah itu data yang dihasilkan diintegrasikan dengan LCD Wiki TFT 3.5 inch dan di kirim ke Arduino Uno agar data yang diterima dapat diolah menjadi perintah - perintah gerak bagi motor stepper melalui driver motor. Pada sistem tersebut terdapat 2 motor stepper yaitu pada motor stepper 1 dan 2, untuk melakukan gerakan panning dan tilting. Sensor limit switch yang terdapat pada sistem berfungsi sebagai saklar untuk motor stepper 1. Cara kerja sensor tersebut dikendalikan oleh Arduino Uno yang dihubungkan dengan Raspberry Pi 4B menggunakan kabel USB 


\section{B. Diagram Alir}

Diagram alir atau flowchart adalah suatu standar untuk menggambarkan proses yang dilakukan oleh sistem. Setiap langkah dalam sistem dinyatakan dalam sebuah simbol dan aliran langkahnya dinyatakan dengan garis yang dilengkapi tanda panah. Pada tahap ini membuat rencana program yang meliputi input dan output yang merupakan gambaran tentang data yang diproses dan informasi yang dihasilkan. Agar program yang disusun dapat terarah dan menghasilkan informasi yang sesuai dengan kebutuhan. Flowchart sistem pada alat dapat dilihat pada Gambar 2.

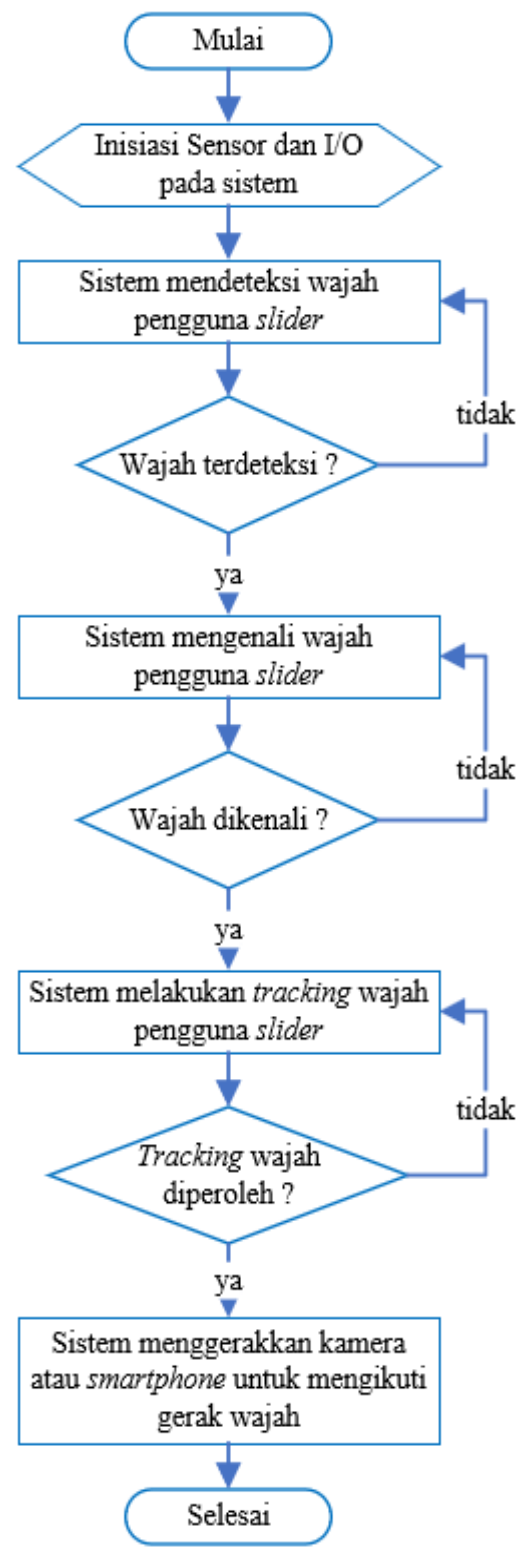

Gambar 2. Flowchart Sistem
C. Perancangan Hardware Slider

1. Perancangan Mekanik

Perancangan mekanik ini meliputi perancangan kerangka desain mekanik alat yang dibuat dengan menggunakan software solidworks untuk mendapatkan gambar yang baik. Kerangka alat ini berbahan alumunim, kaca akrilik, dan plastik $3 \mathrm{D}$ print. Bahan alumunium yang digunakan yaitu T slot, bahan ini digunakan pada rel slider dengan panjang rel $60 \mathrm{~cm}$. Penggunaan bahan bermaterial alumunium bertujuan agar rel slider memiliki ketahanan yang lebih tinggi dan lebih kuat dibandingkan material lainnya sehingga rel tidak mudah patah saat slider dioperasikan.

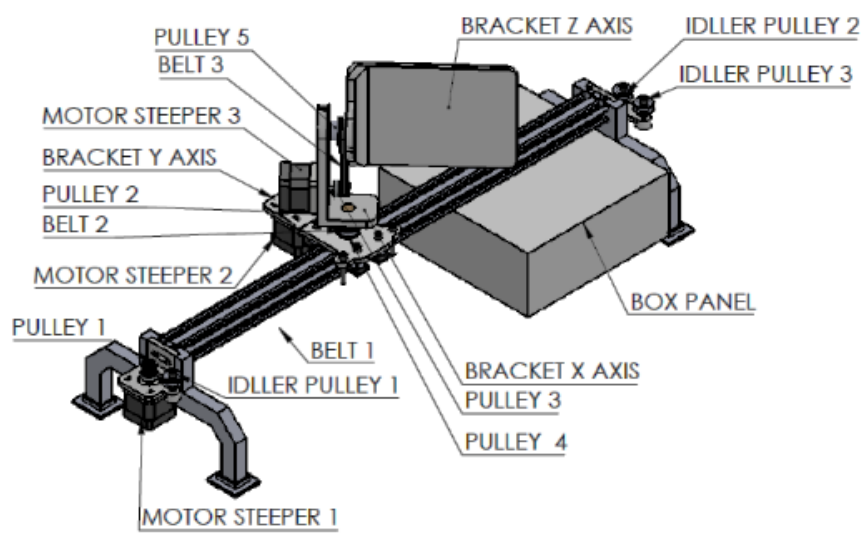

Gambar 3. Desain Mekanik Alat Secara Keseluruhan

\section{Perancangan Rangkaian Elektrik}

Perancangan rangkaian elektrik merupakan gambaran secara utuh tentang sistem pengkabelan dan penguhubungan antar komponen elektrik pada alat yang akan dibuat. Perancangan rangkaian elektrik yang akan dibuat dapat dilihat pada gambar 4 gambar 5, dan gambar 6

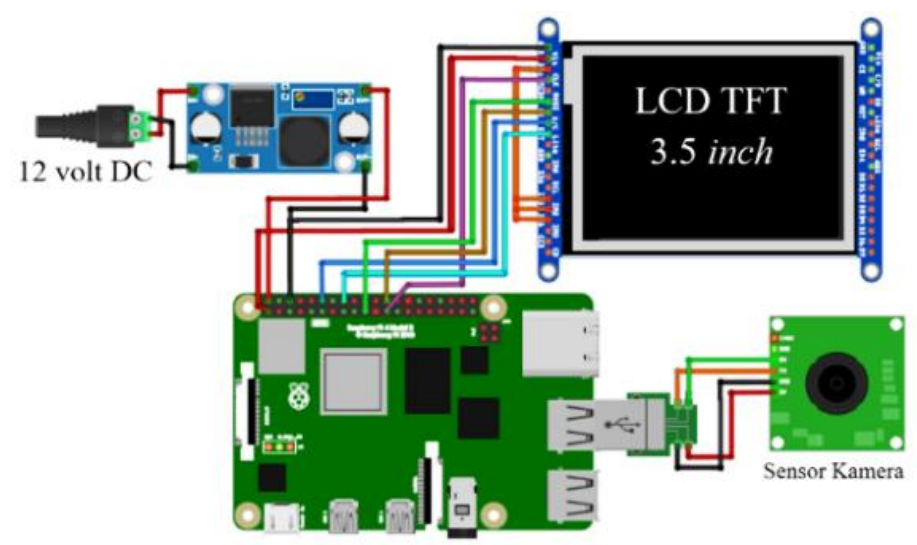

Gambar 4. Rangkaian Elektrik pada Raspberry Pi 4B

Rangkaian elektrik ini dibuat untuk mengetahui bagaimana cara komunikasi antara sensor kamera dan LCD 
TFT 3.5 inch dengan raspberry pi. Komunikasi yang digunakan yaitu komunikasi serial dimana komunikasi serial tersebut menggunakan kabel USB untuk menghubungkan sensor kamera dengan raspberry pi. Sementara itu pengkoneksian LCD dengan raspberry pi dengan menggunakan pin GPIO yang tersedia.

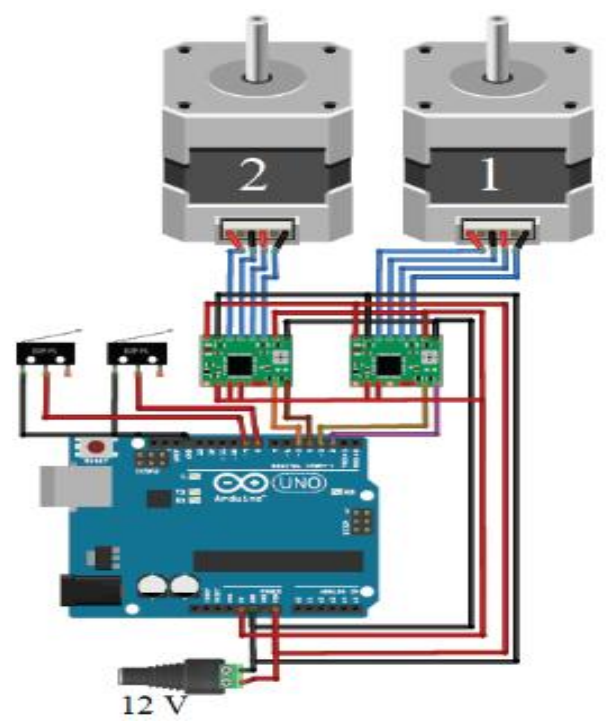

Gambar 5. Rangkaian Elektrik pada Arduino Uno

Rangkaian elektrik tersebut dibuat untuk mengetahui cara pengkoneksian antara driver motor A4988, motor stepper Nema 17, sensor limit switch, dan Arduino Uno. Tabel Konfigurasi antara driver motor A4988, motor stepper Nema 17, sensor limit switch, dan Arduino Uno

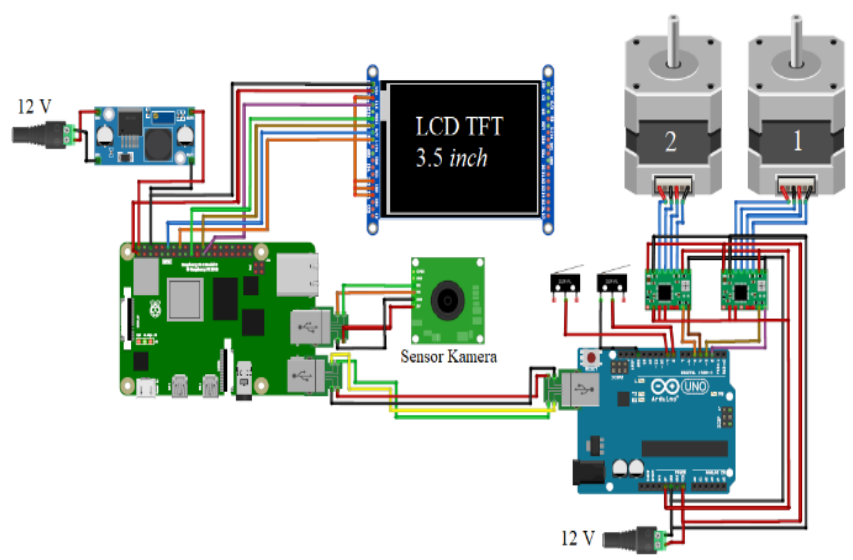

Gambar 6. Rangkaian Elektrik pada Slider

Rangkaian elektrik pada Slider dibuat untuk mengetahui cara pengkoneksian dan pengkomunikasian antara mikrokomputer Raspberry Pi 4B dan mikrokontroller Arduino Uno. Komunikasi dan pengkoneksian antara kedua komponen tersebut menggunakan komunikasi serial, dimana komunikasi serial tersebut menggunakan kabel USB sebagai media pengiriman data.

\section{HASIL DAN PEMBAHASAN}

A. Pengujian Pendeteksian Wajah

Pengujian pendeteksian wajah dilakukan dengan mendeteksi wajah pengguna slider menggunakan modul OpenCV. Pemrogramman python yang disimulasikan pada raspberry pi secara berulang kali mengambil sampel data pendeteksian wajah tersebut untuk memenuhi data pengujian pendeteksian wajah. Hasil pendeteksian wajah menggunkan modul library OpenCV dapat dilihat pada gambar 4.1.

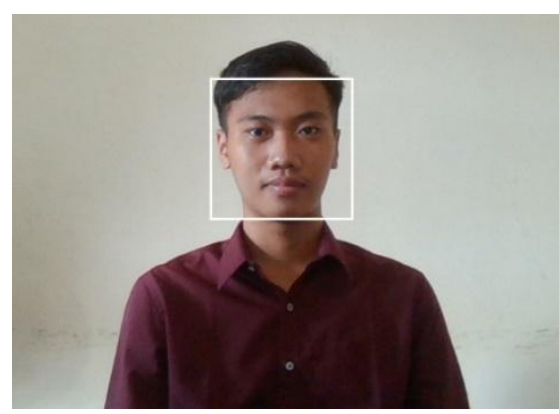

Gambar 7. Hasil Pendeteksian Wajah

Wajah yang terdeteksi ditandai dengan munculnya kotak berwarna putih yang terletak di area sekitar wajah yang telah terdeteksi. Intensitas cahaya yang cukup dan jarak wajah terhadap sensor kamera yang ideal sangat berpengaruh terhadap hasil pedeteksian wajah. Untuk mengetahui hasil pendeteksian wajah berdasarkan jarak pendeteksian dapat dilihat pada tabel 1

Tabel 1 Hasil Pendeteksian Wajah Berdasarkan Jarak Objek

\begin{tabular}{|c|c|c|c|}
\hline No. & Jarak & Hasil & Keterangan \\
\hline 1. & $20 \mathrm{~cm}$ & Tidak Terdeteksi & - \\
\hline 2. & $40 \mathrm{~cm}$ & Terdeteksi & Stabil \\
\hline 3. & $60 \mathrm{~cm}$ & Terdeteksi & Stabil \\
\hline 4. & $80 \mathrm{~cm}$ & Terdeteksi & Stabil \\
\hline 5. & $100 \mathrm{~cm}$ & Terdeteksi & Stabil \\
\hline 6. & $120 \mathrm{~cm}$ & Terdeteksi & Kurang Stabil \\
\hline 7. & $140 \mathrm{~cm}$ & Terdeteksi & Kurang Stabil \\
\hline 8. & $160 \mathrm{~cm}$ & Tidak Terdeteksi & - \\
\hline 9. & $180 \mathrm{~cm}$ & Tidak Terdeteksi & - \\
\hline 10. & $200 \mathrm{~cm}$ & Tidak Terdeteksi & - \\
\hline
\end{tabular}

Pada tabel 1 dapat di jelaskan bahwa jarak wajah terhadap sensor kamera minimal $40 \mathrm{~cm}$ dan maksimal $100 \mathrm{~cm}$. Pada jarak 120 dan 140 wajah masih dapat terdeteksi namun hasil pendeteksian kurang stabil yang ditandai dengan kotak berwarna putih yang berkedip. Oleh karena itu jarak $100 \mathrm{~cm}$ merupakan jarak maksimal yang dapat dicapai oleh sistem dalam mendeteksi wajah. 
B. Pengujian Pengenalan Wajah

Pengujian pengenalan wajah dilakukan dengan menguji sistem dalam mengenali wajah pengguna yang sebelumnya telah mendaftarkan citra wajah menggunakan algoritma haar cascade classifier, kemudian mengambil sampel data pengujian pengenalan wajah tersebut untuk memenuhi data pengujian pengenalan wajah.

Pengujian pengenalan wajah pada raspberry pi terdapat 3 proses yaitu proses pengambilan gambar sebagai datasheet wajah, proses training wajah, dan proses pengenalan atau pencocokkan wajah yang terdeteksi. Hasil pengujian pengambilan wajah sebagai datasheet dapat dilihat pada gambar 8

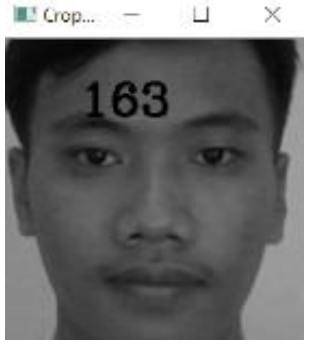

Gambar 8 Proses Pengambilan Wajah Sebagai Datasheet

Pengambilan datasheet wajah dilakukan sebanyak 250 kali. Semakin banyak jumlah datasheet wajah maka semakin mudah algoritma haar cascade classifier dalam mengenali wajah. Namun dikarenakan kapasitas raspberry pi yang terbatas, sistem hanya dapat menampung sekitar 250 gambar wajah untuk setiap penggunaan. Datasheet hasil dari proses pengambilan wajah dapat dilihat pada gambar 9

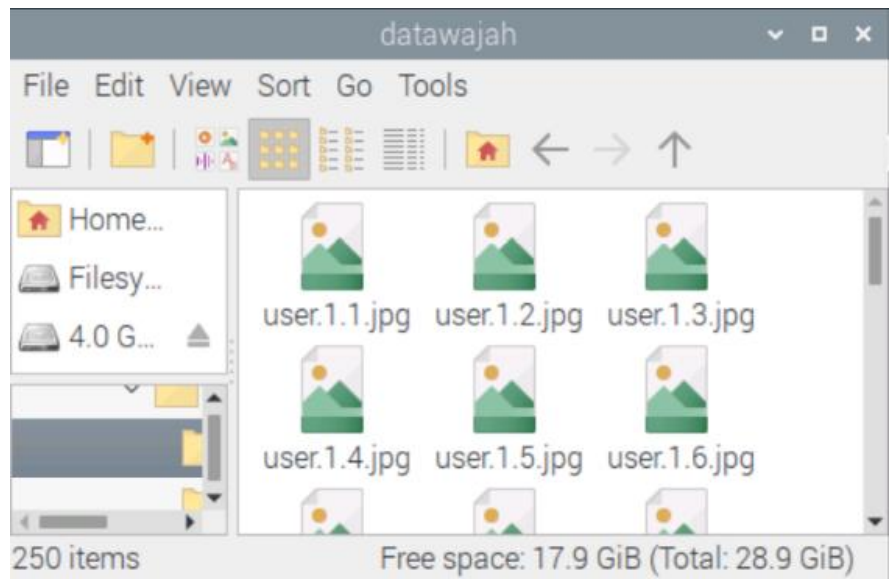

Gambar 9 Datasheet Hasil Proses Pengambilan Wajah

Pengujian training wajah dilakukan dengan membuat file berformat .xml menggunakan data wajah yang telah direkam sebelumnya menggunakan algoritma haar cascade classifier. Hasil taining wajah dapat dilihat pada gambar 10.

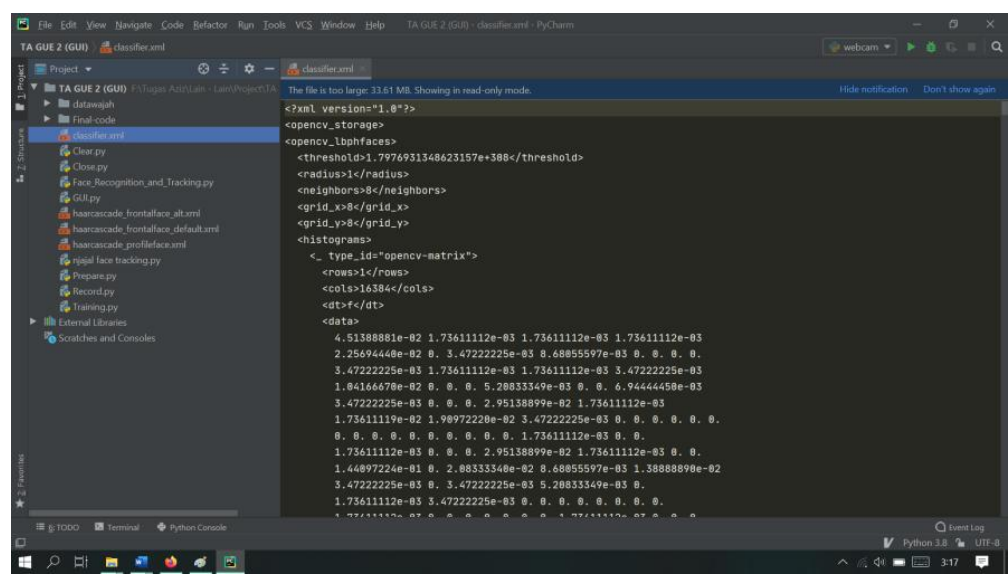

Gambar 10. Hasil Pengujian Training Wajah

Gambar 10.merupakan tampilan file "classifier.xml" yang berisikan data wajah yang sudah dianalisa oleh sistem menggunakan program Local Binary Pattern Histogram (LBPH). LBPH merupakan salah satu metode yang digunakan untuk proses pengolahan fitur wajah. Metode ini mengubah tekstur dari suatu citra wajah menjadi nilai biner, dan nilai tersebut mewakili bagian dari piksel-piksel suatu wajah yang membentuk sebuah lingkaran dan memiliki pusat sebagai acuan terhadap nilai-nilai biner tersebut. Jarak antar kerapatan dari nilai-nilai biner tersebut dinamakan neighbors. Hasil pengujian pengenalan atau pencocokkan wajah yang dapat dikenali maupun tidak dapat dikenali dapat dilihat pada gambar 10 dan gambar 11

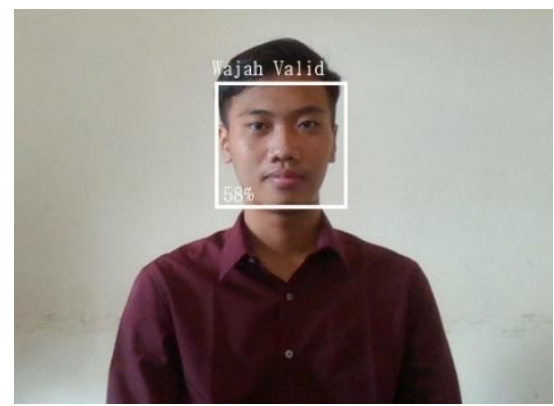

Gambar 10 Hasil Pengujian Pengenalan Wajah Yang Dikenali

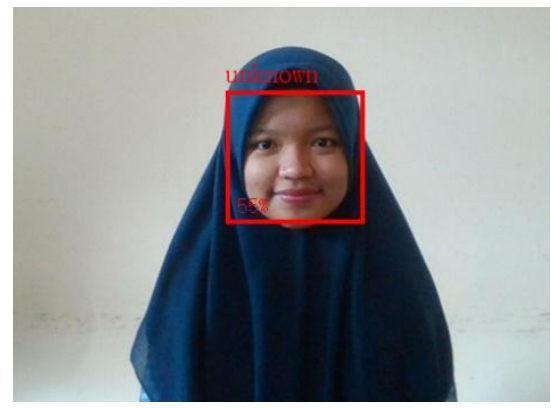

Gambar 11 Hasil Pengujian Pengenalan Wajah Yang Tidak Dikenali 
Dilihat dari gambar 10 dan gambar 11 dapat dijelaskan bahwa wajah yang berhasil dikenali oleh sistem ditandai dengan kotak berwarna putih dan terdapat keterangan "wajah valid" di bagian atas kotak. Sedangkan untuk wajah yang tidak dikenali akan muncul keterangan "Unknown" diatas kotak.

Pada kotak tersebut juga tertera tingkat akurasi pengenalan wajah yang telah dianalisia oleh sistem. Akurasi pengenalan wajah sangat menentukan keberhasilan slider dalam menggerakkan kamera atau smartphone agar selaras dengan pergerakkan wajah yang sudah dikenali. Pengujian terhadap akurasi pengenalan wajah dilakukan dengan menguji sistem pengenalan wajah pada jarak $10 \mathrm{~cm}-100 \mathrm{~cm}$ dan mengamati nilai persentase akurasi pengenalan wajah yang tertera pada kotak pada saat wajah dikenali oleh sistem. Hasil pengujian tingkat akurasi pengenalan wajah dapat dilihat pada tabel 2

Tabel 2 Pengujian Tingkat Akurasi Pengenalan Wajah

\begin{tabular}{|c|c|c|c|c|}
\hline $\begin{array}{l}\text { Penguji } \\
\text { an ke - }\end{array}$ & Jarak & $\begin{array}{c}\text { Hasil } \\
\text { Pengenala } \\
n\end{array}$ & $\begin{array}{c}\text { Akuras } \\
\text { i }\end{array}$ & $\begin{array}{c}\text { Keteranga } \\
\text { n }\end{array}$ \\
\hline 1 & $10 \mathrm{~cm}$ & $\begin{array}{c}\text { Wajah } \\
\text { tidak } \\
\text { dikenali }\end{array}$ & $18,96 \%$ & $\begin{array}{c}\text { Tidak } \\
\text { Berhasil }\end{array}$ \\
\hline 2 & $20 \mathrm{~cm}$ & $\begin{array}{c}\text { Wajah } \\
\text { tidak } \\
\text { dikenali }\end{array}$ & $20,47 \%$ & $\begin{array}{c}\text { Tidak } \\
\text { Berhasil }\end{array}$ \\
\hline 3 & $30 \mathrm{~cm}$ & $\begin{array}{c}\text { Wajah } \\
\text { dikenali }\end{array}$ & $40,24 \%$ & Berhasil \\
\hline 4 & $40 \mathrm{~cm}$ & $\begin{array}{c}\text { Wajah } \\
\text { dikenali }\end{array}$ & $60,76 \%$ & Berhasil \\
\hline 5 & $50 \mathrm{~cm}$ & $\begin{array}{c}\text { Wajah } \\
\text { dikenali }\end{array}$ & $61,57 \%$ & Berhasil \\
\hline 6 & $60 \mathrm{~cm}$ & $\begin{array}{c}\text { Wajah } \\
\text { dikenali }\end{array}$ & $61,54 \%$ & Berhasil \\
\hline 7 & $70 \mathrm{~cm}$ & $\begin{array}{c}\text { Wajah } \\
\text { dikenali }\end{array}$ & $60,78 \%$ & Berhasil \\
\hline 8 & $80 \mathrm{~cm}$ & $\begin{array}{c}\text { Wajah } \\
\text { dikenali }\end{array}$ & $60,67 \%$ & Berhasil \\
\hline 9 & $90 \mathrm{~cm}$ & $\begin{array}{c}\text { Wajah } \\
\text { dikenali }\end{array}$ & $59,88 \%$ & Berhasil \\
\hline 10 & $100 \mathrm{~cm}$ & $\begin{array}{c}\text { Wajah } \\
\text { dikenali }\end{array}$ & $59,80 \%$ & Berhasil \\
\hline \multicolumn{3}{|c|}{ Rata - rata } & $50,47 \%$ & $75 \%$ \\
\hline
\end{tabular}

Dari tabel 2 dapat dijelaskan bahwa dari 10 pengujian pengenalan wajah terdapat 2 pengujian yang menyatakan bahwa sistem tidak dapat mengenali wajah yaitu pada jarak 10 $-20 \mathrm{~cm}$ dan 8 pengujian yang menyatakan bahwa sistem dapat mengenali wajah yaitu pada jarak $30-100 \mathrm{~cm}$. Namun pada jarak $30 \mathrm{~cm}$ akurasi pengenalan wajah mengalami penurunan drastis. Jadi berdasarkan pengujian tersebut sistem pengenalan mempunyai rata - rata akurasi pengenalan wajah sebesar $50,47 \%$.
Tingkat keberhasilan sistem dalam mengenali wajah yaitu sebesar $75 \%$ yang diambil dari 8 kali keberhasilan walapun terdapat 1 kali pengujian yang mengalami penurunan akurasi dari 10 kali pengujian yang telah dilakukan. Sehingga jarak ideal pengenalan wajah yaitu pada jarak $40-100 \mathrm{~cm}$. Tingkat akurasi dipengaruhi jarak wajah terhadap sensor kamera, semakin ideal jarak wajah terhadap jarak sensor kamera maka tingkat akurasi pengenalan akan semakin tinggi mencapai $\pm 60 \%$.

\section{Pengujian Hardware Slider}

Pengujian hardware slider dilakukan dengan menguji mekanik slider dengan beban dan tanpa beban, kemudian menguji motor stepper dalam menggerakkan mekanik slider yang diberi sebuah beban dan tanpa beban, dan menguji rangkaian elektrik pada alat apakah konektivitas antar komponen sudah tersambung dengan baik atau tidak.

\section{Pengujian Mekanik Slider}

Hasil dari pengujian mekanik pada slider meliputi pengujian rel slider, pengujian lengan slider, dan pengujian kaki slider. Hasil pengujian rel slider dapat dilihat pada gambar 11

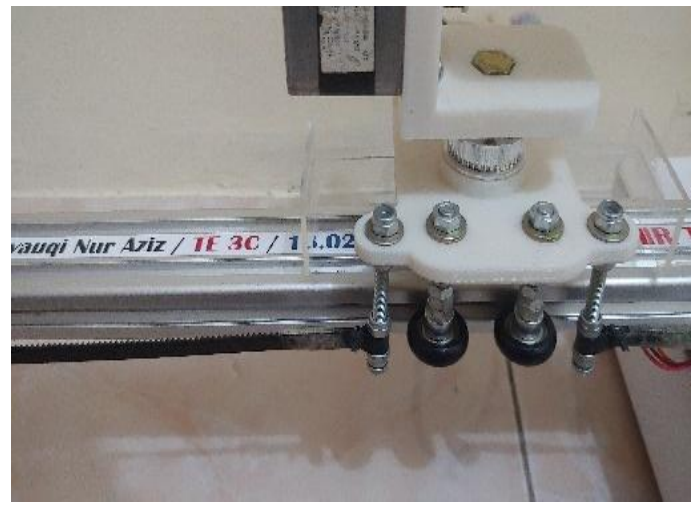

Gambar 12 Hasil Dari Pengujian Rel Slider

Pada gambar 12 merupakan hasil pengujian rel atau lintasan slider. Pada pengujian tersebut rel slider dapat berfungsi dengan baik menopang lengan slider yang bergerak mengikuti pergerakan wajah. Selanjutnya hasil pengujian lengan slider dapat dilihat pada gambar 13

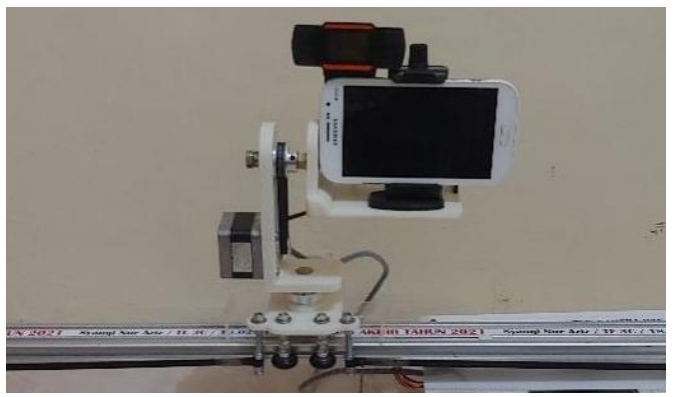

Gambar 13. Hasil Dari Pengujian Pengujian Lengan Slider 
Pada gambar 13. merupakan hasil pengujian lengan slider. Pada pengujian tersebut lengan slider dapat berfungsi dengan baik menopang sensor kamera webcam dan smartphone yang digunakan untuk merekam vidio. Selanjutnya hasil pengujian lengan slider dapat dilihat pada gambar 13

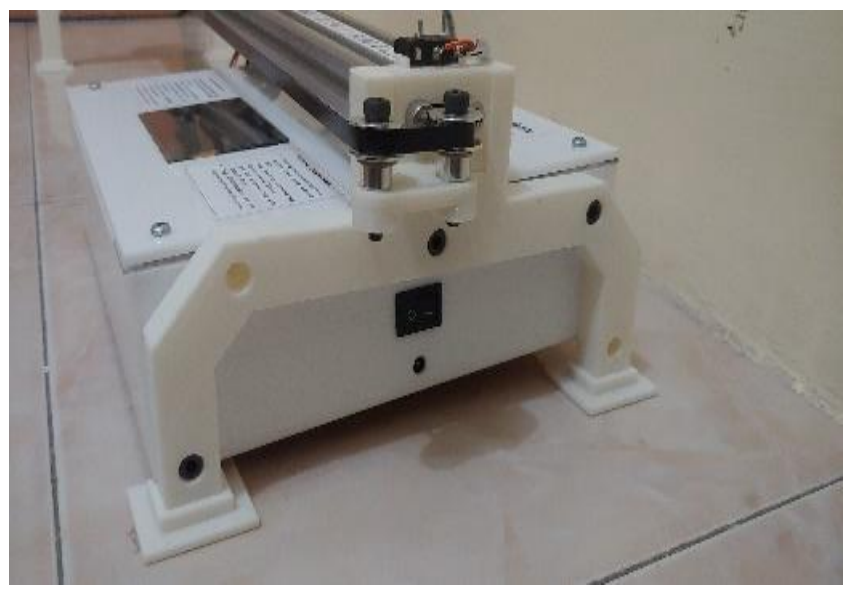

Gambar 14 Hasil Dari Pengujian Pengujian Kaki Slider

Pada gambar 13 merupakan hasil pengujian kaki slider. Pada pengujian tersebut kaki slider dapat berfungsi dengan baik menopang seluruh badan slider beserta komponen - komponen yang tersusun didalamnya.

\section{Pengujian Aktuator Slider}

Proses pengujian dilakukan dengan dua metode. Metode pertama yaitu pengujian motor stepper tanpa beban tambahan. Metode kedua yaitu pengujian motor stepper dengan ditambahkan beban kamera atau smartphone dengan berat \pm 350 gram. Berikut adalah tabel pengujian dari Sumbu X dan Y tanpa menggunakan beban.

Tabel 3 Pengujian Sumbu X Tanpa Beban

\begin{tabular}{|c|c|c|c|}
\hline $\begin{array}{c}\text { Pengujian } \\
\text { ke- }\end{array}$ & $\begin{array}{c}\text { Nilai Aktual } \\
(\mathbf{c m})\end{array}$ & $\begin{array}{c}\text { Nilai } \\
\text { Pembacaan } \\
(\mathbf{c m})\end{array}$ & $\begin{array}{c}\text { Error } \\
(\mathbf{c m})\end{array}$ \\
\hline 1 & 1 & 1 & 0 \\
\hline 2 & 2 & 2 & 0 \\
\hline 3 & 4 & 4 & 0 \\
\hline 4 & 6 & 6 & 0 \\
\hline 5 & 8 & 8 & 0 \\
\hline 6 & 10 & 10 & 0 \\
\hline 7 & 15 & 15 & 0 \\
\hline 8 & 20 & 20 & 0 \\
\hline 9 & 25 & 25 & 0 \\
\hline 10 & 30 & 30 & 0 \\
\hline \multicolumn{3}{|c|}{ Rata-Rata Error } & 0 \\
\hline
\end{tabular}

Tabel 4 Pengujian Sumbu Y Tanpa Beban

\begin{tabular}{|c|c|c|c|}
\hline $\begin{array}{c}\text { Pengujian } \\
\text { ke- }\end{array}$ & $\begin{array}{c}\text { Nilai Aktual } \\
(\mathbf{c m})\end{array}$ & $\begin{array}{c}\text { Nilai } \\
\text { Pembacaan } \\
(\mathbf{c m})\end{array}$ & $\begin{array}{c}\text { Error } \\
(\mathbf{c m})\end{array}$ \\
\hline 1 & 1 & 1 & 0 \\
\hline 2 & 2 & 2 & 0 \\
\hline 3 & 4 & 4 & 0 \\
\hline 4 & 6 & 6 & 0 \\
\hline 5 & 8 & 8 & 0 \\
\hline 6 & 10 & 10 & 0 \\
\hline 7 & 15 & 15 & 0 \\
\hline 8 & 20 & 20 & 0 \\
\hline 9 & 25 & 25 & 0 \\
\hline 10 & 30 & 30 & 0 \\
\hline \multicolumn{3}{|c|}{ Rata-Rata Error } & $\mathbf{0}$ \\
\hline
\end{tabular}

Tabel 3 dan 4 diatas adalah hasil pengujian perbandingan nilai aktual dan nilai pembacaan tanpa beban dengan cara mengukur menggunakan penggaris. Nilai error merupakan nilai selisih antara nilai aktual dengan nilai yang sebenarnya. Setelah melakukan pengujian dari dua sumbu yaitu $\mathrm{X}$ dan Y maka diketahui rata-rata error yaitu 0 .

Pengujian ke-dua dilakukan dengan menambahkan beban kamera atau smartphone dengan berat \pm 350 gram pada lengan slider. Pengujian ini bertujuan untuk mengetahui apakah ada pengaruh saat alat diberi beban kerja. Berikut adalah tabel pengujian dari Sumbu X dan Y dengan menggunakan beban.

Tabel 5 Pengujian Sumbu X Dengan Beban

\begin{tabular}{|c|c|c|c|}
\hline $\begin{array}{c}\text { Pengujian } \\
\text { ke- }\end{array}$ & $\begin{array}{c}\text { Nilai Aktual } \\
(\mathbf{c m})\end{array}$ & $\begin{array}{c}\text { Nilai } \\
\text { Pembacaan } \\
(\mathbf{c m})\end{array}$ & $\begin{array}{c}\text { Error } \\
(\mathbf{c m})\end{array}$ \\
\hline 1 & 1 & 1 & 0 \\
\hline 2 & 2 & 2 & 0 \\
\hline 3 & 4 & 4 & 0 \\
\hline 4 & 6 & 6 & 0 \\
\hline 5 & 8 & 8 & 0 \\
\hline 6 & 10 & 10 & 0 \\
\hline 7 & 15 & 15 & 0 \\
\hline 8 & 20 & 20 & 0 \\
\hline 9 & 25 & 25 & 0 \\
\hline 10 & 30 & 30 & 0 \\
\hline \multicolumn{3}{|c|}{ Rata-Rata Error } \\
\hline
\end{tabular}

Tabel.6 Pengujian Sumbu Y Dengan Beban

\begin{tabular}{|c|c|c|c|}
\hline $\begin{array}{c}\text { Pengujian } \\
\text { ke- }\end{array}$ & $\begin{array}{c}\text { Nilai Aktual } \\
(\mathbf{c m})\end{array}$ & $\begin{array}{c}\text { Nilai } \\
\text { Pembacaan } \\
(\mathbf{c m})\end{array}$ & $\begin{array}{c}\text { Error } \\
(\mathbf{c m})\end{array}$ \\
\hline 1 & 1 & 1 & 0 \\
\hline 2 & 2 & 2 & 0 \\
\hline 3 & 4 & 4 & 0 \\
\hline 4 & 6 & 6 & 0 \\
\hline
\end{tabular}




\begin{tabular}{|c|c|c|c|}
\hline 5 & 8 & 8 & 0 \\
\hline 6 & 10 & 10 & 0 \\
\hline 7 & 15 & 15 & 0 \\
\hline 8 & 20 & 20 & 0 \\
\hline 9 & 25 & 25 & 0 \\
\hline 10 & 30 & 30 & 0 \\
\hline \multicolumn{3}{|c|}{ Rata-Rata Error } \\
\hline
\end{tabular}

Dari tabel pengujian 5 dan 6 diatas didapatkan hasil bahwa sumbu $\mathrm{X}$ dan $\mathrm{Y}$ dapat mengeluarkan hasil yang maksimal walaupun telah diberi beban kamera atau smartphone dengan berat \pm 350 gram pada lengan slider.

\section{KESIMPULAN}

Intensitas cahaya dan jarak objek terhadap sensor kamera sangat berpengaruh pada proses pendeteksian wajah. Semakin tinggi intensitas cahaya yang ditangkap sensor dan semakin ideal jarak objek dengan sensor kamera yaitu antara $40-100 \mathrm{~cm}$ maka semakin mudah sistem dalam mendeteksi dan mengenali wajah. Kualitas sensor kamera yang digunakan sangat berpengaruh terhadap proses pendeteksian, pengenalan, dan tracking wajah. Penggunaan material pada mekanik slider juga sangat berpengaruh pada proses pergerakan slider, semakin kuat material yang digunakan maka pergerakan slider akan semakin kokoh dan stabil.Pada proses penyelarasan gerak slider terhadap gerak wajah terdapat delay atau waktu tunda selama 3 detik setiap $10 \mathrm{~cm}$ gerakan. Hal ini dikarenakan OpenCV membutuhkan waktu untuk mendeteksi, mengenali, dan mengirim koordinat gerakan ke Arduino secara bersamaan. Slider dapat bekerja dengan menyelaraskan gerak kamera atau smartphone dengan gerak wajah dengan rata - rata keberhasilan penyelarasan sebesar 41,69\%.

\section{Referensi}

[1] E. R. Sinatriya, M. I. A. Timur, and I. Candradewi, "Model Tracking Pembicara Dalam Perekaman Video Otomatis Pada Kelas Cendekia," IJEIS (Indonesian J. Electron. Instrum. Syst., vol. 9, no. 1, p. 1, 2019, doi: 10.22146/ijeis.27818.

[2] O. P. Pangestu, "Rancang Bangun Pengendalian Slider Otomatis Pada Kamera Digital Menggunakan Metode Fuzzy Logic Sugeno Berbasis Mikrokontroler," Universitas Andalas, 2018.

[3] C. Lesmana et al., "Implementasi Face Recognition menggunakan Raspberry pi untuk akses Ruangan Pribadi," J. Infra Petra, pp. 2-5, 2019.

[4] D. Kurniadi, "Slider Kamera Tanpa Kabel Laporan Proyek Akhir," Lap. Tugas Akhir Tek. Elektron. Polibatam, 2018.

[5] A. Y. Kristanto, "Pusat Apresiasi Fotografi Di Yogyakarta," e-journal.uajy.ac.id, pp. 12-40, 2015.
S. Audina, "Pengembangan Aplikasi Teknik Pergerakan Kamera Sinematografi Berbasis 3D Augmented Reality Sebagai Media Pembelajaran Teknik Pengambilan Gambar Bergerak Untuk Kelas XI multimedia di SMK N 7 Yogyakarta," Universitas Negeri Yogyakarta, 2018.

[7] J. Y. Mambu, A. Wahyudi, Z. Reinaldo, and T. Braif, "Robot Perekam Objek Berbasis Face Tracking," CogITo Smart J., vol. 3, no. 2, p. 164, 2017, doi: 10.31154/cogito.v3i2.67.164-172.

[8] S. Al-Aidid and D. Pamungkas, "Sistem Pengenalan Wajah dengan Algoritma Haar Cascade dan Local Binary Pattern Histogram," J. Rekayasa Elektr., vol. 14, no. 1, pp. 62-67, 2018, doi: 10.17529/jre.v14i1.9799.

[9] L. B. Prianggodo, "Perancangan Object Tracking Robot Berbasis Image Processing Menggunakan Raspberry Pi," Universitas Muhammadiyah Surakarta, 2016.

[10] I. Mat, M. R. Mohd Kassim, A. N. Harun, and I. M. Yusoff, "Smart Agriculture Using Internet of Things," 2018 IEEE Conf. Open Syst. ICOS 2018, no. August, pp. 54-59, 2019, doi: 10.1109/ICOS.2018.8632817.

[11] Rs-Components, "Datasheet Raspberry Pi Model B," 2019.

[12] I. Pranata and S. Nuryadi, "Rancang Bangun Mesin Cetak PCB Berbasis Arduino Menggunakan Metode CNC (Computer Numerical Control)," Ijets.Uty, 2019.

[13] J. Sugianto, "Tugas Akhir Simulasi Penerangan Jalan Umum Otomatis Pada Jalan Tol," Universitas Muhammadiyah Sumatera Utara, 2019.

[14] Farnell, "Datasheet Arduino Uno," vol. 38, no. 1. 2017.

[15] I. A. Nugraha, F. Pradana, and A. Arwan, "Pengembangan Sistem Manajemen Notulensi dan Dokumentasi Rapat Berbasis Web (Studi Kasus : Jurusan Teknik Informatika Fakultas Ilmu Komputer Universitas Brawijaya)," j-ptiik.ub.ac.id, vol. 4, no. 4, pp. 1273-1280, 2020.

[16] Minebea Mitsumi, "Datasheet Motor Stepper NEMA 17," pp. 18-21, 2020.

[17] D. A. Siregar and Hambali, "Alat Pembasmi Hama Tanaman Padi Otomatis Berbasis Mikrokontroler Menggunakan Tegangan Kejut Listrik," JTEIN J. Tek. Elektro Indones., vol. 1, no. 2, pp. 55-62, 2020.

[18] Wiki, "Datasheet 3.5inch RPi Display," 2016.

[19] Ghifari Fikri Yuviyanto, "Simulasi Penggunaan Sensor Limit Switch Dan Motor DC Pada Operasional Miniatur Lift 3 Lantai Dengan Tampilan Human Machine Interface (HMI) Berbasis PLC Schneider Modicon TM221CE16R," Universitas Diponegoro, 2018 . 